\title{
When do You Suspect Immune Deficiency in a Child with
}

\section{Eczema?}

\author{
Rachna S Mohite ${ }^{1}$, Sagar Bhattad ${ }^{2}$
}

\begin{abstract}
Eczematous dermatitis, also known as atopic dermatitis (AD), is a chronic inflammatory skin disease. It globally affects $15-20 \%$ of children and $1-3 \%$ of adults. Patients with eczema are more prone to develop allergic manifestations like allergic rhinitis, asthma, and $80 \%$ usually develop either of them or both. Children and adults with primary immune deficiencies (PIDs) are not only prone to infections, but they develop allergies, autoimmunity, and malignancies also. Eczematous dermatitis is a common finding among several PIDs and many of these patients first present to a dermatologist. Primary immune deficiencies that can present with eczema are hyper-lgE syndrome, Wiskott-Aldrich syndrome, IPEX, etc. Recognizing the warning signs of an underlying PID can help clinicians in the early diagnosis of an underlying immune deficiency. In this paper, we discuss in detail the pathomechanism of eczema in PID and provide a simple approach to PIDs presenting with eczema.
\end{abstract}

Keywords: Atopic dermatitis, Eczema, Primary immune deficiency.

Pediatric Infectious Disease (2022): 10.5005/jp-journals-10081-1335

\section{INTRODUCTION}

Eczematous dermatitis, also known as atopic dermatitis (AD), is a chronic inflammatory skin disease. It globally affects $15-20 \%$ of children and $1-3 \%$ of adults. ${ }^{1}$ The onset is usually in early childhood and significantly affects the quality of life of these patients. Patients with eczema are more prone to develop allergic manifestations like allergic rhinitis, asthma, and $80 \%$ usually develop either of them or both. ${ }^{2}$

\section{Pathogenesis of Eczema}

Atopic dermatitis is a multifactorial disease without any definite pathomechanism. It is caused by a complex interplay of the disrupted epithelial barrier, inflammation, immune dysregulation along with genetic and environmental factors. There are two theories namely "inside out" vs "outside in". However, it remains unclear if the epidermal dysfunction precedes the immune dysregulation or vice versa.

Disruption of the epithelial barrier gives the allergens access to the inflammatory Langerhans and dendritic cells which release proinflammatory cytokines. This gives rise to a Th2-mediated cytokine release and IgE production by B cells (Fig. 1), which is responsible for edema and pruritis. As the disease progresses, there is a shift in the response from Th2 to Th1 pathway.

\section{Immune Deficiency and Eczema}

At present, over 430 different primary immune deficiencies (PIDs) have been identified. Children and adults with PIDs are not only prone to infections; they develop allergies, autoimmunity, and malignancies as well. Primary immune deficiencies are now better known as inborn errors of immunity (IEI), highlighting the broad spectrum of manifestations in these diseases. About $70 \%$ of people with PID exhibit skin manifestations (such as bacterial, fungal, or viral infections and/or eczema), and these signs may be among the primary presenting symptomatology of a child with PID. ${ }^{2}$ Eczematous dermatitis is a common finding among several PIDs and many of these patients first present to a dermatologist. It would
1,2Division of Pediatric Immunology and Rheumatology, Department of Pediatrics, Aster CMI Hospital, Bengaluru, Karnataka, India

Corresponding Author: Sagar Bhattad, Division of Pediatric Immunology and Rheumatology, Department of Pediatrics, Aster CMI Hospital, Bengaluru, Karnataka, India, Phone: +91 9779433934, e-mail: drsagarbhattad@gmail.com

How to cite this article: Mohite RS, Bhattad S. When do You Suspect Immune Deficiency in a Child with Eczema? Pediatr Inf Dis 2022;4(1):26-30.

Source of support: Nil

Conflict of interest: None

be very essential for dermatologists and general care physicians to be aware of the warning signs of an underlying PID when a patient presents with eczema. Enlisted below are some of the PIDs which often present with eczema as a prominent manifestation. ${ }^{3}$

\begin{tabular}{|c|c|c|}
\hline PID/IEI & Gene mutation & Inheritance \\
\hline $\begin{array}{l}\text { Classical hyper-lgE syndrome } \\
\text { (Job's syndrome) }\end{array}$ & STAT3 & $A D$ \\
\hline \multirow[t]{3}{*}{ Hyper-IgE syndrome } & DOCK8 & $\mathrm{AR}$ \\
\hline & PGM3 & AR \\
\hline & TYK2 & $A R$ \\
\hline Netherton syndrome & SPINK5 & AR \\
\hline Wiskott-Aldrich syndrome & WAS & X-linked recessive \\
\hline $\begin{array}{l}\text { Immune dysregulation, poly- } \\
\text { endocrinopathy, enteropathy, } \\
\text { X-linked (IPEX) }\end{array}$ & FOXP3 & X-linked recessive \\
\hline
\end{tabular}

$A D$, autosomal dominant; $A R$, autosomal recessive

\section{Why Eczema in PID?}

IgE antibodies play an important role in the pathogenesis of atopic diseases. IL-4 and IL-13 upregulate IgE production, whereas 


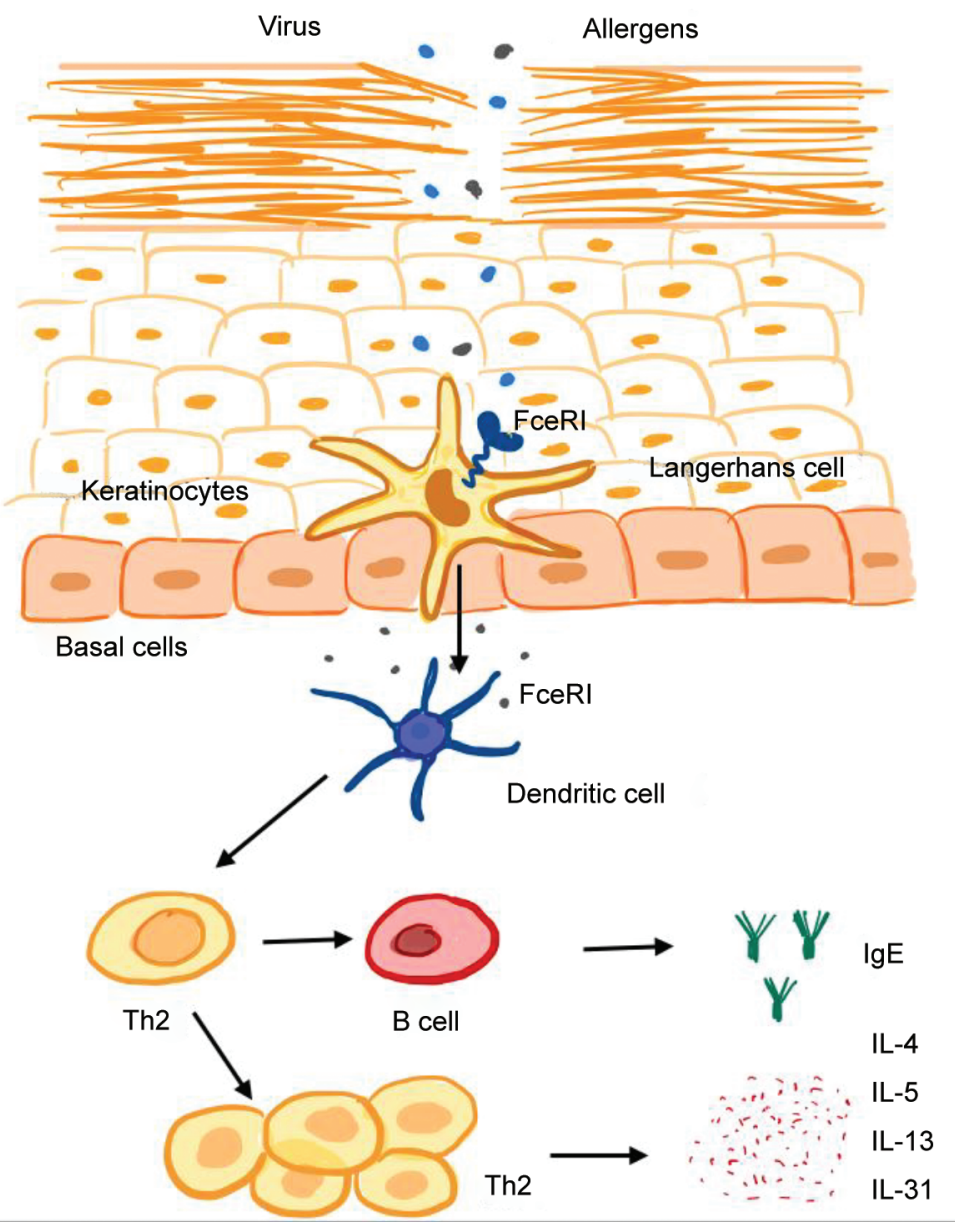

Fig. 1:Th2-mediated signaling in atopic dermatitis

interferon-gamma (IFN $\gamma$ ) and IL-10 repress IgE production. Patients with the hyper-IgE syndrome (e.g., DOCK8 deficiency, STAT3 deficiency) have sustained IL-4 signaling which leads to increased IgE production. Whereas patients with Treg cell deficiency (e.g., IPEX) or dysfunction (e.g., WAS) have decreased IL-10 signaling which in turn leads to high IgE levels.

The binding of IgE to high-affinity Fc receptors (FcERI) on mast cells and basophils causes them to release potent inflammatory mediators (such as histamine and leukotrienes), enzymes, and cytokines. IgE also binds to FceRI on Langerhans cells, dendritic cells, and B cells facilitating allergen uptake by antigen-presenting cells, thereby enhancing presentation to T and B cells. This in turn leads to varied atopic manifestations, including severe eczema.

In the next section, we shall discuss a few cases and understand how one can diagnose an immune deficiency in a patient presenting with eczema.

\section{Case 1}

A 13-year-old, boy presented with recurrent pyoderma from the third year of his life. He would develop recurrent cutaneous abscesses and had undergone incision and drainage of pus on multiple occasions. He also had chronic severe eczema and was being treated with topical steroids. Past history was also significant for recurrent oral candidiasis. He now presented with fever and rapid breathing for the past 1 week.

\section{Family History}

His father had had recurrent skin infections from a young age and had a pathological fracture involving the bones of his left forearm after a trivial fall.

\section{On Examination}

He had coarse facial features, a high arched palate, bulbous nose, and scoliosis. Respiratory examination - crepitations in the right infrascapular area.

\section{Evaluation}

Hemogram: $\mathrm{Hb}-9 \mathrm{~g} / \mathrm{dL}, \mathrm{TC}-16,000 / \mathrm{mm}^{3}\left(\mathrm{~N}_{60} \mathrm{~L}_{22} \mathrm{M}_{6} \mathrm{E}_{12}\right)$, PC-230,000/ $\mathrm{mm}^{3}$.

HIV rapid card test-Negative.

Immunoglobulins - Ig G-1,600 mg/dL, IgA-80 mg/dL, IgM-100 $\mathrm{mg} / \mathrm{dL}, \mathbf{l g} \mathrm{E}-\mathbf{4 , 2 0 0} \mathrm{U} / \mathrm{L}(\mathrm{N}<60)$.

Nitroblue tetrazolium test (NBT), dihydrorhodamine test (DHR) Normal.

Blood culture-Staphylococcus aureus.

Father was evaluated and was found to have very high IgE levels $(3,400 \mathrm{U} / \mathrm{L})$.

HIES score: 43 (> 40 highly suggestive of AD-HIES) (Table 1)

Genetic test: Pathogenic heterozygous mutation in STAT3 


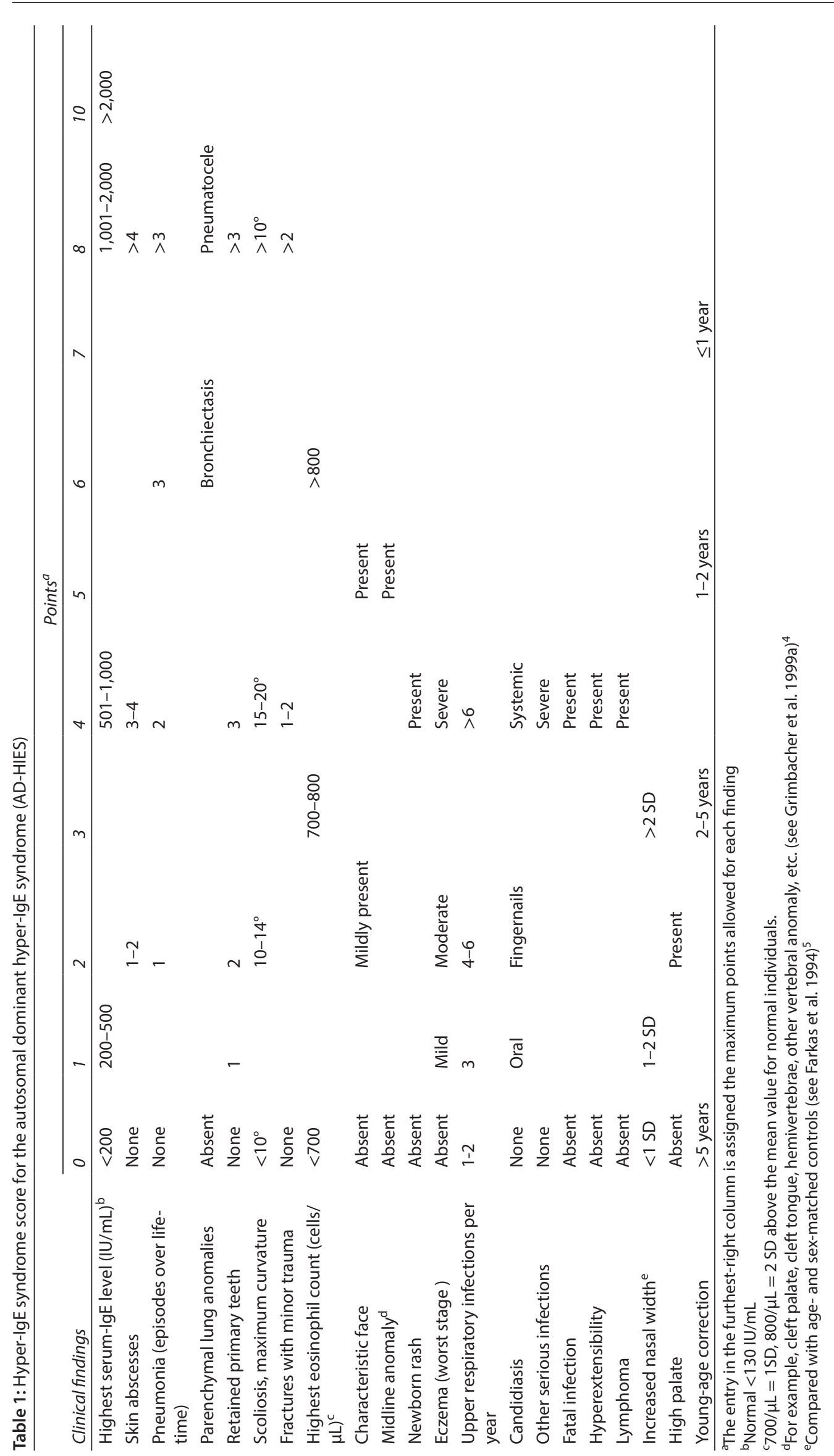


Diagnosis: Hyper-IgE syndrome (AD) (Algorithm 1)

\section{Algorithm 1 (Flowchart 1)}

Flowchart 1: Approach to AD—hyper-lgE syndrome

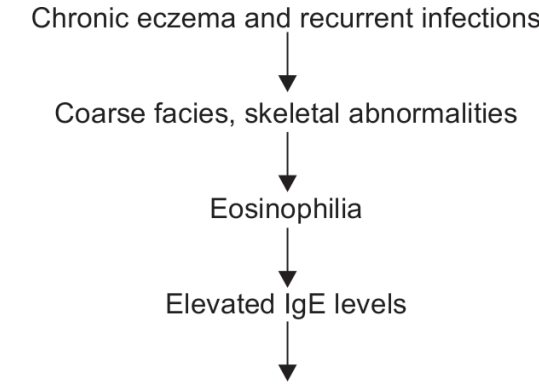

High $\lg E$ and recurrent skin infection in father

Hyper-IgE syndrome (AD)

\section{Message}

- In a child with chronic eczema, recurrent infections, skeletal abnormalities with high IgE levels-Think of AD-HIES!

- HIES score is a useful screening tool in children presenting with chronic eczema. A high score warrants further evaluation.

See algorithm (Flowchart 1)

\section{Case 2}

A 6-year-old, girl presented with eczema from a young age. She was on regular follow-up with the dermatologist and despite treatment, continued to have severe eczema and repeated skin infections. She also had had recurrent ear infections warranting treatment with oral antimicrobials. At the age of 5, she developed multiple warts over her body and had extensive molluscum contagiosum.

\section{Family History}

She was born to a consanguineously married couple. No history of any sibling losses.

\section{On Examination}

She had severe eczema in the flexures of her arms, neck, and groin area and hyperpigmentation of the oral mucosa (Figs $2 \mathrm{~A}$ and $\mathrm{B}$ ).

\section{Evaluation}

Hemogram: $\mathrm{Hb}-9 \mathrm{~g} / \mathrm{dL}, \mathrm{TC}-14,600 / \mathrm{mm}^{3}\left(\mathrm{~N}_{62} \mathrm{~L}_{20} \mathrm{M}_{3} \mathrm{E}_{15}\right)$, PC-242,000/ $\mathrm{mm}^{3}$.

HIV rapid card test-Negative.

$\lg \mathrm{E}-2400 \mathrm{UL}(<60)$.

Genetic studies: Homozygous pathogenic mutation in DOCK8 gene.

Diagnosis: Hyper-IgE syndrome (AR) due to DOCK8 defect (Algorithm 2).

\section{Algorithm 2 (Flowchart 2)}

Flowchart 2: Approach to DOCK8 gene mutation

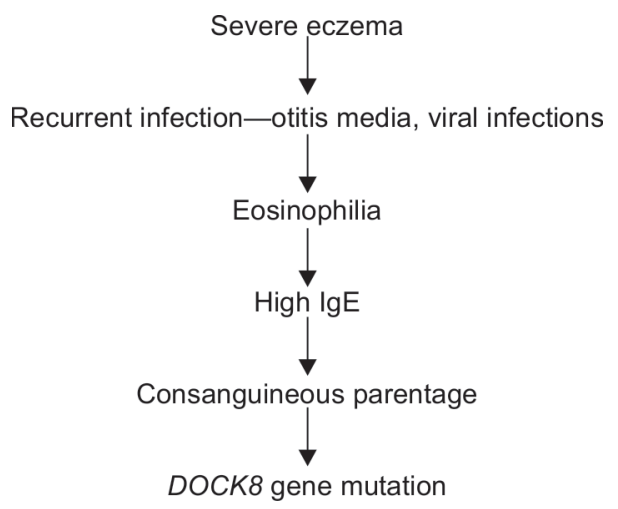

Message

In a child with chronic eczema, think of an immune deficiency in presence of unusual viral infections.

\section{See algorithm (Flowchart 2)}

\section{Case 3}

A 3-year-old boy presented with recurrent episodes of pyoderma from the first year of life. He had severe eczema and was being treated with topical steroids by a dermatologist. He was hospitalized with an episode of pneumonia.

\section{Family History}

He was born of a non-consanguineous marriage. The family had lost a male child at the age of 2.5 years, who had persistent thrombocytopenia and bleeding manifestations.

\section{Evaluation}

Hemogram: $\mathrm{Hb}-10 \mathrm{~g} / \mathrm{dL}, \mathrm{TC}-13,000 / \mathrm{mm}^{3}\left(\mathrm{~N}_{65} \mathrm{~L}_{20} \mathrm{M}_{6} \mathrm{E}_{9}\right)$ $\mathrm{PC}-35,000 / \mathrm{mm}^{3}$.

HIV rapid card test: Negative.

MPV-5 fl (7-11).

Peripheral smear: Presence of small platelets.

Genetic studies: Mutation in the WAS gene

Diagnosis: Wiskott-Aldrich syndrome (Algorithm 3)

\section{See Algorithm (Flowchart 3)}

Flowchart 3: Approach to Wiskott-Aldrich syndrome Repeated skin infections and chronic eczema in a male

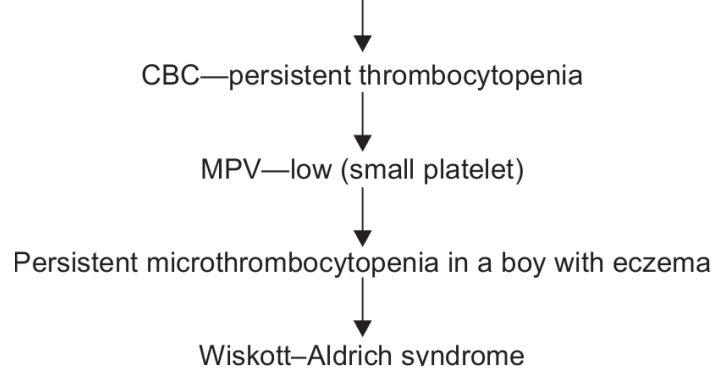

Message

- In boys with chronic eczema, one must always look at the platelet counts. Presence of thrombocytopenia in a boy with eczema Think of Wiskott-Aldrich Syndrome (WAS) 

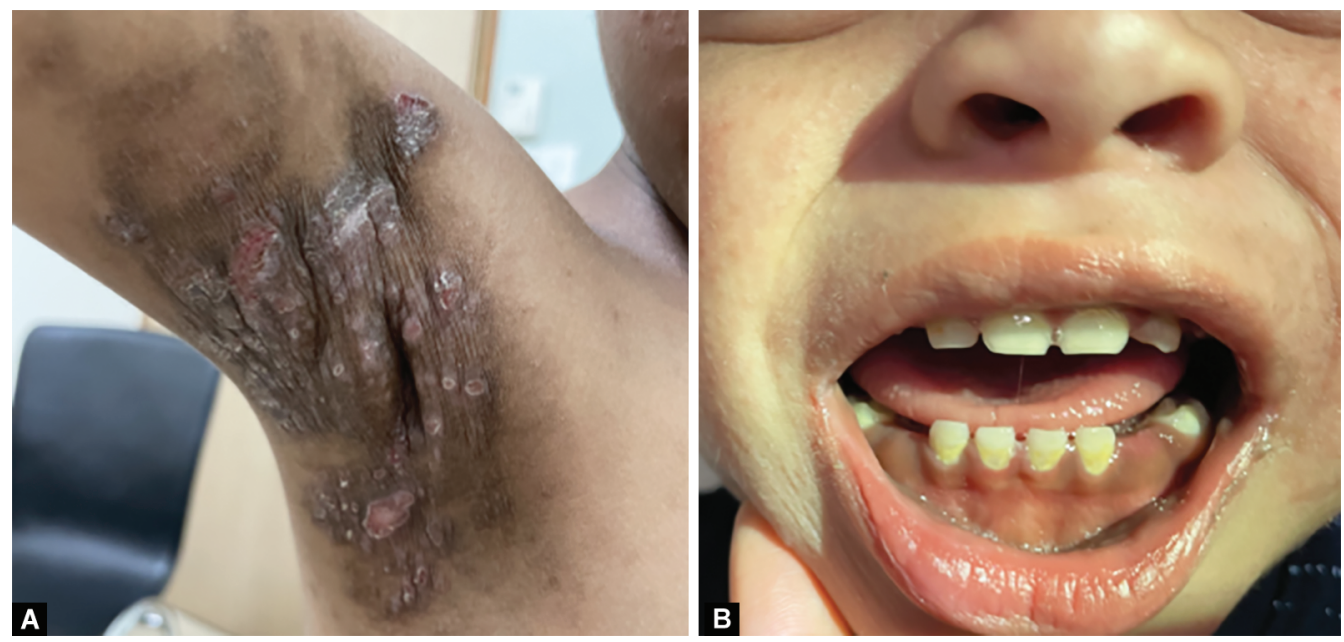

Figs 2A and B: (A) Eczema in the axilla; (B) Mucosal hyperpigmentation

- In boys with persistent thrombocytopenia, look at the mean platelet volume (MPV). Low MPV in this setting is WAS unless proven otherwise.

- Family history of affected siblings - think of a genetic disorder.

\section{Case 4}

A 2-year-old boy presented with chronic eczema from early infancy. He was diagnosed with type 1 diabetes mellitus at the age of 1 . He had intermittent episodes of loose stools that were being treated with antibiotics.

\section{Family History}

He was born of a non-consanguineous marriage. Two brothers had died before the age of 3 years with severe infections.

\section{Evaluation}

Hemogram: $\mathrm{Hb}-10.5 \mathrm{~g} / \mathrm{dL}, \mathrm{TC}-10,000 / \mathrm{mm}^{3}\left(\mathrm{~N}_{65} \mathrm{~L}_{25} \mathrm{M}_{5} \mathrm{E}_{2}\right)$, PC-350,000/ $\mathrm{mm}^{3}$.

HIV rapid card test: Negative.

$\lg \mathrm{E}-920 \mathrm{U} / \mathrm{L}$.

Genetic test (exome sequencing): Mutation in FOXP3 gene

Diagnosis: Immune dysregulation, Polyendocrinopathy, Enteropathy, X-linked (IPEX) (Algorithm 4)

\section{See Algorithm (Flowchart 4)}

Flowchart 4: Approach to IPEX syndrome

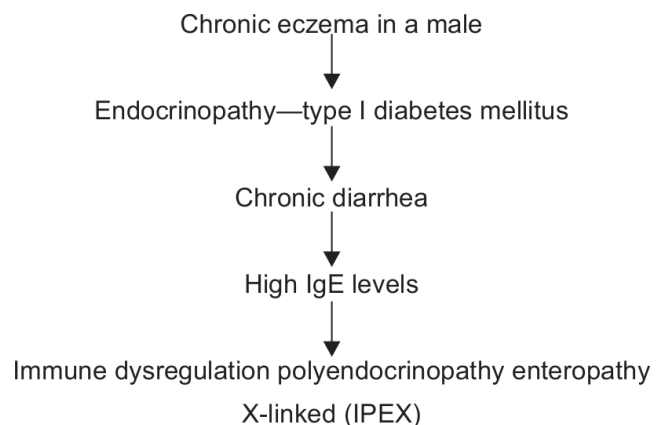

\section{Message}

Triad of eczema + enteropathy + endocrinopathy - Think of IPEX.
When should one evaluate for PIDs in a child with eczema?

- The onset of eczema in the neonatal period.

- The unusual severity of eczema.

- Associated with recurrent skin/systemic infections.

- Associated with recurrent viral infections (e.g., molluscum contagiosum).

- Presence of skeletal and connective tissue abnormalities.

- Eczema with bleeding manifestations.

- Persistent thrombocytopenia.

- Colitis.

- Polyendocrinopathies.

- Positive family history - consanguinity, sibling death/severe infections.

\section{Take-home Message}

- In a child with chronic eczema, one must consider a possibility of an underlying immune deficiency.

- Chronic eczema with unusual viral infections-Think of hyperIgE syndrome (AR-HIES).

- The presence of skeletal abnormalities on the background of severe eczema is a strong pointer toward AD-HIES.

- In a boy with severe eczema, always look at the platelet counts. Thrombocytopenia + eczema in a boy is WAS, unless proven, otherwise.

- Family history can give important clues to the diagnosis of a PID in a child presenting with eczema.

\section{References}

1. Nutten S. Atopic dermatitis: global epidemiology and risk factors. Ann Nutrit Metabol 2015;66(Suppl. 1):8-16. DOI: 10.1159/000370220.

2. Gilaberte Y, Pérez-Gilaberte JB, Poblador-Plou B, et al. Prevalence and comorbidity of atopic dermatitis in children: a large-scale population study based on real-world data. J Clin Med 2020;9(6):1632. DOI: 10.3390/jcm9061632.

3. Bojtor $A E$, Sárdy $M$, Maródi L. Az elsődleges immunhiánybetegségek bőrmanifesztációi [cutaneous manifestations in primary immunodeficiency diseases]. Orv Hetil 2018;159(23):937-947. DOI: 10.1556/650.2018.30994Hungarian.

4. Grimbacher B, Holland SM, Gallin Jl, et al. Hyper-IgE syndrome with recurrent infections-an autosomal dominant multisystem disorder. N Engl J Med 1999;340(9):692-702.

5. Farkas LG, ed. Anthropometry of the Head and Face. Lippincott Williams \& Wilkins; 1994. 